\title{
Patient-Reported Satisfaction and Associated Changes in Health and Behavior Pre- and Post- Project INSPIRE: a Comprehensive Hepatitis C Care Coordination Program
}

Regan Deming ( $\sim$ rdeming@health.nyc.gov )

New York City Department of Health and Mental Hygiene https://orcid.org/0000-0003-1576-0996

Anna Mageras

New York City Department of Health and Mental Hygiene

Caroline Davidson

New York City Department of Health and Mental Hygiene

Marie Bresnahan

New York City Department of Health and Mental Hygiene

Sheila Reyonoso

Montefiore Medical Center

Brooke Wyatt

Icahn School of Medicine at Mount Sinai

Fabienne Laraque

New York City Department of Health and Mental Hygiene

Research article

Keywords: hepatitis C, care coordination, patient survey, health behavior, partially overlapping sample

Posted Date: January 16th, 2020

DOl: https://doi.org/10.21203/rs.2.21061/v1

License: (c) (i) This work is licensed under a Creative Commons Attribution 4.0 International License. Read Full License 


\section{Abstract}

Background

Individuals infected with hepatitis $\mathrm{C}(\mathrm{HCV})$ often present with co-morbidities and complex socio-behavioral risk factors. Project INSPIRE was a care coordination and telementoring demonstration project which aimed to treat and cure HCV-infected patients while providing them with services and education to improve overall health outcomes and self-sufficiency. We examined changes in HCV-related health and behavior associated with completion of Project INSPIRE (the "intervention").

Methods

Patients were enrolled into Project INSPIRE at clinical sites where they received HCV clinical care paired with care coordination services. Baseline and post-intervention surveys were distributed to participants in-person at a clinical site and/or via mail at two time-points, one before and one after the intervention. Surveys were mailed back to the researchers by participants, and participant-identifying information was used to link survey responses to clinical data for each respondent. Logistic models using generalized estimating equations to account for partially overlapping observations examined the association between intervention participation and changes in self-reported overall health, emergency department (ED) visits and hospitalizations in the past 6 months, drug and alcohol use in the past 6 months, HCV knowledge, and general self-efficacy, adjusting for potential demographic and sociobehavioral confounding variables.

Results

The response rates for complete and partial surveys were $14.0 \%$ of 883 for baseline and $9.9 \%$ of 1,552 for postintervention. In multivariable analyses ( $N=269$, of which 50 were paired and 219 were unpaired), INSPIRE intervention participation was associated with a decreased odds of self-reported ED visits (OR: $0.34,95 \% \mathrm{Cl}$ : $0.20-0.57$ ), hospitalizations (OR: $0.30,95 \% \mathrm{Cl}: 0.16-0.57$ ), alcohol use (OR: $0.35,95 \% \mathrm{Cl}: 0.18-0.69$ ), and injection drug use (OR: $0.09,95 \% \mathrm{Cl}: 0.02-0.34$ ), and a $6.8 \%$ (Cl: $1.6-12.2 \%$ ) increase in reported self-efficacy $(p=0.01)$.

\section{Conclusions}

Survey results suggest that INSPIRE successfully improved participant health behavior and self-efficacy, indicating the intervention's value to patients, providers, and insurance companies beyond the immediate benefits of HCV treatment and cure. Participants also had a generally positive experience working with their care teams, indicating that further research should explore how an individualized care team can improve retention and patient referral rates compared with the HCV standard of care.

\section{Introduction}

Hepatitis C virus (HCV) causes an infection that, when left untreated, can lead to liver damage, including cirrhosis, hepatocellular carcinoma, and liver failure (1). Currently, an estimated 2.4 million persons ( $1 \%$ of the population) in the United States (US) (2) and approximately 116,00 persons in New York City (NYC) (3) are chronically infected with HCV. People most at risk for infection include injection drug users, those currently and formerly incarcerated, and those in the "baby boomer" birth cohort (individuals born between 1945 and 1965) (4). 
High-needs patients, including those with mental illness, substance use disorders, and/or a lack of social support, may face a variety of barriers to HCV care and treatment, including limited access to health care services and difficulties navigating the health care system $(5,6)$. Care coordination programs addressing these barriers for chronic diseases have shown improved outcomes in similar populations $(7,8)$.

Project INSPIRE (INSPIRE) was a comprehensive 3-year evidence-based intervention designed by the NYC Department of Health and Mental Hygiene and funded by a Centers for Medicaid and Medicare Innovation Award, to link NYC residents chronically infected with HCV to HCV-related medical care, initiate HCV treatment, and ultimately achieve sustained virologic response (SVR, which is clinically defined as cure). INSPIRE was implemented at two large NYC hospitals located in neighborhoods with high rates of HCV infection: the South Bronx and East Harlem. Patients were assigned to care coordinators who worked alongside HCV clinical providers to support patients throughout their medical care. Care coordinators provided services designed to improve overall health, health behavior, HCV knowledge, and the capacity to cope with ongoing and arising health issues. These services included linkage to HCV care, referrals to other social services, health promotion sessions, alcohol and drug use counseling, and medication adherence support. As a demonstration project, INSPIRE was designed to monitor patient progress toward cure and evaluate treatment outcomes using clinical and care coordination data (9). Analysis of INSPIRE clinical outcomes has shown that participants enrolled in the program had better odds of initiating treatment and achieving SVR compared with similar HCV-infected individuals not enrolled in the program (10).

In addition to measuring clinical outcomes, as part of our comprehensive evaluation of INSPIRE, we assessed changes in self-reported patient health and health-related behaviors, HCV knowledge, self-efficacy, and patient satisfaction. To assess these outcomes, we used baseline and post-intervention surveys, an approach commonly used in evaluations of other care coordination programs (11-14). We hypothesized that intervention participation would be positively associated with improved health outcomes, increased HCV knowledge, and ability to manage HCV infection and other health conditions.

\section{Methods}

Survey distribution and eligibility

Between January 1, 2015 and February 28, 2017, Project INSPIRE enrolled 2,775 patients across the two clinical sites, while care coordination and data collection were conducted through August 31, 2017. Enrollment eligibility into INSPIRE required individuals to be HCV-positive NYC residents over the age of 18 and beneficiaries of Medicaid and/or Medicare.

The baseline survey was distributed by the care coordinators between August 2016 and March 2017, and the post-intervention survey was distributed between November 2016 and September 2017. Survey participation was voluntary.

INSPIRE participants enrolled up to one month prior to the start of survey distribution were eligible for the baseline survey. INSPIRE participants who were discharged and re-enrolled into the program were considered eligible for the baseline survey if they had received no or minimal INSPIRE services (no more than one health promotion session and/or no initial assessment) prior to their first discharge. INSPIRE participants were eligible 
to receive a post-intervention survey within one month of their last visit with their care coordinator regardless of whether they had completed a baseline survey.

\section{Survey and data collection}

Each survey packet included an information flier, the survey in English (6 pages) or Spanish (8 pages), an informed consent form, and a stamped, pre-addressed envelope to return the survey to New York City Department of Health and Mental Hygiene (NYC DOHMH). All materials were available in English and Spanish and distributed according to patients' language preference. Surveys and informed consent forms were to be completed by participants without the assistance of their care coordinator or clinician (the care team). Respondents were directed to contact the NYC DOHMH evaluation team using the phone number on the information flier with questions or for clarification in order to limit care team involvement. Participants also had the option to call the evaluation team and complete the survey over the phone. For each returned baseline or post-intervention survey, respondents were mailed a \$25 gift card. Respondents were contacted by phone if response clarification was necessary or questions were unanswered. All survey packets contained the same information and all surveys asked the same questions, although during the first few weeks of survey deployment a few minor changes were made to the survey itself. These included adding graphics to the cover page to make it more appealing, changing the responses from fill in the blank to categorical for number of ED visits and hospital nights in the past 6 months and removing the patient satisfaction questions from the baseline survey since the questions were only intended for post survey respondents.

Secondary data source

INSPIRE clinical sites submitted program data to NYC DOHMH in a clinical database which included participant name, contact information, sociodemographic information, dates of enrollment, care coordination services, treatment initiation and completion, discharge and SVR/cure status. First and last name of respondents and enrollment site listed on the returned surveys were used to identify respondents in the clinical database to link the two datasets.

Measures of interest

The main goal of the analysis was to assess changes in overall self-reported health status and health-related behavior, HCV-related knowledge, and self-efficacy in regard to managing health between baseline and postintervention. Seven outcomes of interest were collected in both the baseline and the post-intervention survey: selfreported overall health (measured using the single general self-rated health question (GSRH) (15)) (outcome 1); self-reported number of emergency department (ED) visits (outcome 2), number of nights hospitalized (outcome 3), any drug use (outcome 4), and any alcohol consumption (outcome 5) in the past 6 months; HCV knowledge (assessed using a 14-question HCV knowledge scale adapted from the validated Brief HCV Knowledge Scale) (16) (outcome 6); and respondent self-efficacy (assessed using a 13-question self-efficacy measure adapted from the validated Patient Activation Measure) (17). The self-efficacy measure was sufficiently different from the original Patient Activation Measure, so the original scoring guide could not be used to score the adapted measure. Exploratory factor analysis (EFA) and subsequent factor scoring was instead used to generate respondent scores (outcome 7). Both surveys also included questions on demographics, specifically education and marital status. 
Secondary goals were to measure patient adherence to their HCV medication and patient satisfaction with their HCV care coordinator, HCV medical provider, and the INSPIRE health promotion sessions at the end of the intervention. HCV medication adherence was assessed via two adapted questions (18) asking about the respondent's adherence during the preceding four weeks. Respondent satisfaction with their care coordinator and clinician was measured with questions from the Patient Reactions Assessment (19) regarding quality of information received, perceived quality of communication, perceived affection, and perceived respect. Satisfaction with health promotion sessions was assessed using ten questions developed by the INSPIRE evaluation team. Responses were recoded into Agree (agree + strongly agree) and Neutral/Disagree (neutral + disagree + strongly disagree), in keeping with patient satisfaction analysis convention (12). Responses of "not applicable" were coded as missing.

\section{Factor analysis}

To generate self-efficacy scores, we used EFA to identify latent constructs ("factors") underlying responses to the self-efficacy questions in the survey and to score responses based on this factor structure (20). The data were checked and met the assumptions for EFA analysis (21-25). Factors were then extracted using principal axis factoring and oblique rotation (24), taking into account non-normal distribution of responses (26) and communalities (multiple questions defining the same factor) $(20,25)$. A one-factor structure was hypothesized, based on prior assessment of the unmodified Patient Activation Measure (17) and confirmed based on factor retention guidelines $(24,25)$. Each patient's self-efficacy question responses were then scored and standardized based on this one-factor structure. To account for the subjective methodologies used to determine factor retention (27) and compute factor scores (20), a sensitivity analysis was performed using respondents' mean self-efficacy score generated from the original Patient Activation measure scoring guide in place of factor score. Crude and adjusted generalized estimating equation (GEE) models for a respondent's mean self-efficacy score were calculated and the results were compared with models using factor scores.

Statistical analysis

Response rates

Survey responses were classified as complete, partial, break-off, ineligible, and lack of response ("refusal"), per American Association for Public Opinion Research (AAPOR) guidance (28). Surveys with responses for $>80 \%$ of the questions were counted as complete, those with responses for $50-80 \%$ of the questions were counted as partial, and those with responses for $<50 \%$ of the questions were deemed too incomplete to process (break-off, ineligible, or lack of response) and subsequently excluded from analyses. Response rates were calculated using the AAPOR definition for mail surveys of specifically named persons (all surveys were returned via mail except for 2 conducted over the phone), both for only complete surveys and for complete and partial surveys. The AAPOR publicly available Survey Outcome Rate Calculator version 4.0 (mail_SN) was used to conduct the calculations (29).

\section{Power limitations}

Baseline and post-intervention surveys received from the same respondent were classified as "paired"; when only the baseline or post-intervention survey was available, it was classified as "unpaired." Because of the limited number of paired surveys available, we included all eligible surveys. In order to maximize power, we avoided sub- 
analyses because of small numbers, and we only used covariates shown to be important for the outcome in existing literature rather than based on statistical significance $(13,30)$.

\section{Summary analyses}

Descriptive statistics, including statistical tests of association, were used to compare sociodemographic characteristics between individuals with paired and unpaired surveys and between baseline and post-intervention survey respondents within the unpaired group. We evaluated differences between (paired vs unpaired) and within groups (unpaired baseline vs unpaired post) to determine what results in subsequent analyses we could attribute to the effect of INSPIRE versus differences in response rates (unpaired group). Wilcoxon-Mann Whitney tests were used to assess continuous variables, and chi-square tests were used to assess categorical variables. By comparing the between and within groups together, rather than directly baseline and post, all observations were independent and we did not need to account for the overlapping nature of the sample. Prior to analyses, values of "unknown" and "refused" were coded as missing and excluded from all summary analyses. Following descriptive analyses, missing values for survey variables were imputed (see Missing Data below). Differences in HCV knowledge were assessed by comparing the percentage of correct responses among baseline and postintervention questions using chi-square tests that accounted for the overlapping sample (31). For the summary analyses, data about alcohol and IDU use in the last 6 months were collected at time of enrollment during the comprehensive assessment while for the outcome analyses survey responses were used.

\section{Missing data}

To include all eligible surveys in the multivariable analyses, multiple imputation (MI) was used to preserve surveys with missing responses. Given that social desirability bias likely influenced the response rates to some questions, we assumed that the data were missing not at random (MNAR). However, we chose to proceed with MI because the technique can still produce unbiased results under the MNAR mechanism (32). After assessing associations between various demographic or survey variables and survey completeness using t- and chi-square significance tests, the final variables included in the imputation process were survey type, age, gender, race/ethnicity, marital status, social support, HIV status, mental health status, and all survey variables assessed as one of the seven primary outcomes specified above, except for self-efficacy. Missing values for the selfefficacy questions were not imputed to simplify subsequent EFA.

MI with chained equations, generating 20 imputed datasets, was performed (33) using all variables included as predictors for imputation for each variable with missing values and using marital status and survey type as auxiliary variables. MI was performed using the IVEware stand-alone SRCWare package (34). To account for the MI, PROC MIANALYZE was used in the outcome analyses to generate a single estimate for each regression coefficient by synthesizing the values from all imputed datasets.

\section{Outcome analyses}

The changes in the following outcomes before and after receiving the INSPIRE intervention were assessed using GEE regression models: (1) overall health, (2) number of ED visits in the preceding 6 months, (3) number of nights spent in the hospital in the preceding 6 months, (4) any alcohol and (5) any drug use in the preceding 6 months, (6) HCV knowledge, and (7) self-efficacy. The self-reported health outcomes (1-3) were analyzed as ordinal multinomial variables, while the self-reported behavioral variables (4 and 5) were analyzed as binary 
variables. The HCV knowledge score (range: 0-100\%) and self-efficacy scores (range: 0-5) were analyzed as continuous variables (6 and 7).

GEE regression models, with exchangeable correlation structure, were used because of the non-independence of the paired baseline and post-intervention survey responses, and the non-normal distributions of some variables [35-38]. To account for the exchangeable correlation structure for binary and ordinal outcomes, the alternating logistic regression (ALR) method was used in the models for these outcomes. The ALR approach uses odds ratios (ORs) to model within-respondent associations and calculates the odds of a change in the response to a given measure in the post-intervention survey relative to the baseline survey (35).

The initial confounders used in all adjusted models were age at enrollment, gender, race/ethnicity, education level, social support, HIV status, and mental health status, selected based on preexisting literature $(13,30)$ since not all variables included in the summary analyses were included in the model due to over dispersion. To account for model non-convergence, variables found to not contribute to the model based on the literature, followed by testing the statistical significance with the outcome, were removed (36). Race/ethnicity was removed from the alcohol use model, and race/ethnicity and education level were removed from the drug use model.

All analyses were performed using SAS 9.4 (Cary, North Carolina).

Patient satisfaction with their care team and adherence to medication were summarized and the proportion of responses for each question were calculated. Patient satisfaction was grouped into categories of information, communication, and respect for each member of the care team.

\section{Results}

Demographics and response rates

During July 2016-February 2017, 883 patients enrolled in Project INSPIRE and were eligible for the baseline survey. During October 2016-August 2017, 1,552 participants were discharged from Project INSPIRE and were eligible for the post-intervention survey. From this population, 113 complete and 6 partial baseline surveys and 145 complete and 5 partial post-intervention surveys were received (Fig. 1). Of the 119 baseline surveys received, 2 were conducted on the phone while no post surveys were conducted over the phone. Of these 269 eligible surveys, 50 were paired and 219 were unpaired. The response rates for complete surveys were $13.3 \%$ for baseline and $9.5 \%$ for post-intervention, while the response rates for complete and partial surveys were $14.0 \%$ for baseline and $9.9 \%$ for post-intervention. Of the 25 patients who completed both the baseline and post surveys the average time between completing the baseline and the post surveys was 184 days (SD +/-60 days) or about 6 months.

Tests of association showed that respondents with paired and unpaired surveys, as well as respondents returning only either baseline or post-intervention surveys were mostly similar for almost all demographic characteristics. The only statistically significant difference was that among respondents with unpaired surveys, post-intervention-only survey respondents tended to be older than baseline-only survey respondents (mean age 59.4 years compared with 53.8 years, respectively, $p=0.0004$ ) (Table 1 ). Although we might have been underpowered to detect differences in demographic, clinical, and sociobehavioral characteristics between groups of respondents who submitted only a baseline or only a post-intervention survey, we considered these groups similar enough to mimic paired surveys and merit inclusion in the GEE models. 
Table 1

Survey Respondent Characteristics, Compared across Paired and Unpaired Baseline and Post-Intervention Surveys and across Unpaired Baseline and Post-Intervention Surveys

\begin{tabular}{|c|c|c|c|c|c|c|c|c|c|c|}
\hline & \multicolumn{5}{|c|}{ Between Group } & \multicolumn{5}{|c|}{ Within Unpaired Group } \\
\hline & \multicolumn{2}{|c|}{ Paired $(n=25)$} & \multicolumn{3}{|c|}{$\begin{array}{l}\text { Unpaired }(n= \\
219)\end{array}$} & \multicolumn{2}{|c|}{$\begin{array}{l}\text { Baseline-only } \\
(\mathrm{n}=94)\end{array}$} & \multicolumn{3}{|c|}{$\begin{array}{l}\text { Post- } \\
\text { intervention- } \\
\text { only }(n=125)\end{array}$} \\
\hline & Mean & SD & Mean & SD & $\begin{array}{l}p- \\
\text { value }\end{array}$ & Mean & SD & Mean & SD & $p$-value \\
\hline Age & 58.2 & 7.49 & 56.9 & 11.45 & 0.47 & 53.8 & 11.91 & 59.4 & 10.48 & $0.0004 *$ \\
\hline & $\mathrm{N}$ & $\%$ & $\mathrm{~N}$ & $\%$ & $\begin{array}{l}\mathrm{p}- \\
\text { value }\end{array}$ & $\mathrm{N}$ & $\%$ & N & $\%$ & $p$-value \\
\hline Gender & 25 & & 219 & & & 94 & & 125 & & \\
\hline Male & 18 & 72.0 & 138 & 63.0 & 0.37 & 62 & 66.0 & 76 & 60.8 & 0.43 \\
\hline Female & 7 & 28.0 & 81 & 37.0 & & 32 & 34.0 & 49 & 39.2 & \\
\hline Race/Ethnicity & 25 & & 219 & & 0.87 & 94 & & 125 & & 0.47 \\
\hline Black & 9 & 36.0 & 85 & 38.8 & & 36 & 38.3 & 49 & 39.2 & \\
\hline White & 2 & 8.0 & 27 & 12.3 & & 9 & 9.6 & 18 & 14.4 & \\
\hline Hispanic & 13 & 52.0 & 97 & 44.3 & & 46 & 48.9 & 51 & 40.8 & \\
\hline Other & 1 & 4.0 & 10 & 4.6 & & 2 & 2.1 & 7 & 5.6 & \\
\hline $\begin{array}{l}\text { Income - } \\
\text { monthly }\end{array}$ & 25 & & 209 & & 0.12 & 88 & & 121 & & 0.82 \\
\hline$<\$ 800$ & 14 & 56.0 & 150 & 71.8 & & 65 & 73.9 & 85 & 70.2 & \\
\hline$\$ 801-1200$ & 10 & 40.0 & 45 & 21.5 & & 18 & 20.5 & 27 & 22.3 & \\
\hline >\$1200 & 1 & 4.0 & 14 & 6.7 & & 5 & 5.7 & 9 & 7.4 & \\
\hline $\begin{array}{l}\text { Education } \\
\text { Level }\end{array}$ & 25 & & 215 & & 0.33 & 91 & 100 & 124 & & 0.54 \\
\hline $\begin{array}{l}\text { Less than 9th } \\
\text { grade }\end{array}$ & 2 & 8.0 & 20 & 9.3 & & 7 & 7.7 & 13 & 10.5 & \\
\hline 9-11th grade & 13 & 52.0 & 76 & 35.3 & & 33 & 36.3 & 43 & 34.7 & \\
\hline $\begin{array}{l}\text { High school } \\
\text { graduate/GED } \\
\text { or equivalent }\end{array}$ & 5 & 20.0 & 59 & 27.4 & & 28 & 30.8 & 31 & 25.0 & \\
\hline
\end{tabular}

*Significant at the $a=.05$ level 


\begin{tabular}{|c|c|c|c|c|c|c|c|c|c|c|}
\hline \multirow[b]{2}{*}{$\begin{array}{l}\text { Some college } \\
\text { or AA degree }\end{array}$} & \multicolumn{5}{|c|}{ Between Group } & \multicolumn{5}{|c|}{ Within Unpaired Group } \\
\hline & 2 & 8.0 & 44 & 20.5 & & 19 & 20.9 & 25 & 20.2 & \\
\hline $\begin{array}{l}\text { College } \\
\text { graduate or } \\
\text { above }\end{array}$ & 3 & 12.0 & 16 & 7.4 & & 4 & 4.4 & 12 & 9.7 & \\
\hline Marital Status & 24 & & 215 & & 0.59 & 91 & & 124 & & 0.21 \\
\hline Married & 2 & 8.3 & 42 & 19.5 & & 12 & 13.2 & 30 & 24.2 & \\
\hline Widowed & 2 & 8.3 & 21 & 9.8 & & 7 & 7.7 & 14 & 11.3 & \\
\hline $\begin{array}{l}\text { Divorced or } \\
\text { separated }\end{array}$ & 5 & 20.8 & 45 & 20.9 & & 23 & 25.3 & 22 & 17.7 & \\
\hline $\begin{array}{l}\text { Single, never } \\
\text { married }\end{array}$ & 11 & 45.8 & 89 & 41.4 & & 41 & 45.1 & 48 & 38.7 & \\
\hline Partnered & 3 & 12.5 & 11 & 5.1 & & 6 & 6.6 & 5 & 4.0 & \\
\hline $\begin{array}{l}\text { Prefer not to } \\
\text { answer }\end{array}$ & 1 & 4.2 & 7 & 3.3 & & 2 & 2.2 & 5 & 4.0 & \\
\hline $\begin{array}{l}\text { Insurance } \\
\text { Type }\end{array}$ & 25 & & 218 & & 0.41 & 93 & & 125 & & 0.21 \\
\hline Medicaid & 20 & 80.0 & 150 & 68.8 & & 70 & 75.3 & 80 & 64.0 & \\
\hline Medicare & 4 & 16.0 & 42 & 19.3 & & 14 & 15.1 & 28 & 22.4 & \\
\hline Dually Eligible & 1 & 4.0 & 26 & 11.9 & & 9 & 9.7. & 17 & 13.6 & \\
\hline $\begin{array}{l}\text { Alcohol Past } 6 \\
\text { Months }\end{array}$ & 25 & & 211 & & 0.41 & 88 & & 123 & & 0.64 \\
\hline Yes & 7 & 28.0 & 44 & 20.9 & & 17 & 19.3 & 27 & 22.0 & \\
\hline No & 18 & 72.0 & 167 & 79.1 & & 71 & 80.7 & 96 & 78.0 & \\
\hline $\begin{array}{l}\text { IDU Past } 6 \\
\text { Months }\end{array}$ & 25 & & 206 & & 1.0 & 85 & & 121 & & 0.77 \\
\hline Yes & 3 & 12.0 & 25 & 12.1 & & 11 & 12.9 & 14 & 11.6 & \\
\hline No & 22 & 88.0 & 181 & 87.9 & & 74 & 87.1 & 107 & 88.4 & \\
\hline HIV Comorbid & 25 & & 219 & & 0.24 & 94 & & 125 & & 0.06 \\
\hline Yes & 9 & 36.0 & 55 & 25.1 & & 29 & 30.9 & 26 & 20.8 & \\
\hline
\end{tabular}




\begin{tabular}{|c|c|c|c|c|c|c|c|c|c|c|}
\hline No & 16 & 64. & 164 & 74.9 & & 65 & 69.1 & 99 & 79.2 & \\
\hline $\begin{array}{l}\text { Diabetes } \\
\text { Comorbid }\end{array}$ & 25 & & 219 & & 0.34 & 94 & & 125 & & 0.11 \\
\hline Yes & 2 & 8.0 & 33 & 15.1 & & 10 & 10.6 & 23 & 18.4 & \\
\hline No & 23 & 92.0 & 186 & 84.9 & & 84 & 89.4 & 102 & 81.6 & \\
\hline $\begin{array}{l}\text { History of } \\
\text { Incarceration }\end{array}$ & 19 & & 147 & & 0.73 & 65 & & 82 & & 0.09 \\
\hline Yes & 11 & 57.9 & 79 & 53.7 & & 40 & 61.5 .7 & 39 & 47.6 & \\
\hline No & 8 & 42.1 & 68 & 46.3 & & 25 & 38.5 & 43 & 52.4 & \\
\hline $\begin{array}{l}\text { Mental Health } \\
\text { Comorbidities }\end{array}$ & 25 & & 212 & & 0.38 & 88 & & 124 & & 0.75 \\
\hline Yes & 9 & 36.0 & 96 & 45.3 & & 41 & 46.6 & 55 & 44.4 & \\
\hline No & 16 & 64.0 & 116 & 54.7 & & 47 & 53.4 & 69 & 55.6 & \\
\hline $\begin{array}{l}\text { Social } \\
\text { Support } \\
\text { (Family } \\
\text { anddor } \\
\text { Friends) }\end{array}$ & 25 & & 219 & & 0.11 & 94 & & 125 & & 0.72 \\
\hline Yes & 24 & 96.0 & 184 & 84.0 & & 78 & 83.0 & 106 & 84.8 & \\
\hline No & 1 & 4.0 & 35 & 16.0 & & 16 & 17.0 & 19 & 15.2 & \\
\hline $\begin{array}{l}\text { Location of } \\
\text { Clinical Site }\end{array}$ & 25 & & 219 & & 0.24 & 94 & & 125 & & 0.7 \\
\hline South Bronx & 16 & 64.0 & 113 & 51.6 & & 49 & 52.1 & 64 & 51.2 & \\
\hline Harlem & 9 & 36.0 & 106 & 48.4 & & 45 & 47.9 & 61 & 48.8 & \\
\hline $\begin{array}{l}\text { Neighborhood } \\
\text { Poverty Level }\end{array}$ & 25 & & 219 & & & 94 & & 125 & 125 & 0.61 \\
\hline$<5 \%$ & 0 & $0.0 \%$ & 1 & $0.5 \%$ & & 0 & $0.0 \%$ & 1 & $0.8 \%$ & \\
\hline 5 to $<10 \%$ & 3 & $12.0 \%$ & 13 & $5.9 \%$ & & 4 & $4.3 \%$ & 9 & $7.2 \%$ & \\
\hline 10 to $<20 \%$ & 4 & $16.0 \%$ & 45 & $20.5 \%$ & & 20 & $21.3 \%$ & 25 & $20.0 \%$ & \\
\hline
\end{tabular}




\begin{tabular}{|lcrllllll|}
\hline & \multicolumn{3}{c}{ Between Group } & \multicolumn{5}{c|}{ Within Unpaired Group } \\
\hline 20 to $<30 \%$ & 5 & $20.0 \%$ & 54 & $24.7 \%$ & 25 & $26.6 \%$ & 29 & $23.2 \%$ \\
\hline 30 to $<40 \%$ & 8 & $32.0 \%$ & 82 & $37.4 \%$ & 32 & $34.0 \%$ & 50 & $40.0 \%$ \\
\hline 40 to $100 \%$ & 5 & $20.0 \%$ & 24 & $11.0 \%$ & 13 & $13.8 \%$ & 11 & $8.8 \%$ \\
\hline & & & & & & & & \\
\hline
\end{tabular}

Prior to conducting multiple imputation, chi-square tests were conducted to compare the distribution of missingness between the complete and partial surveys for each of the analysis and auxillary variables used in the multiple imputation. Significant differences were found for education level $(p=0.01)$ and marital status $(p=$ 0.004) (Table 2). 
Table 2

Comparison of Missingness between Complete and Partially Complete Surveys for Variables used in Analysis and Multiple Imputation

\begin{tabular}{|c|c|c|c|c|c|}
\hline \multirow[b]{2}{*}{ Analysis Variables } & \multicolumn{2}{|c|}{$\begin{array}{l}\text { Complete Surveys }(N= \\
159)\end{array}$} & \multicolumn{2}{|c|}{$\begin{array}{l}\text { Partial Surveys }(N= \\
110)\end{array}$} & \multirow[b]{2}{*}{$\begin{array}{l}\mathrm{p}- \\
\text { value }\end{array}$} \\
\hline & $\mathrm{N}$ & $\%$ & $\mathrm{~N}$ & $\%$ & \\
\hline \multicolumn{6}{|l|}{ Age } \\
\hline Missing & 0 & $0.0 \%$ & 0 & $0.0 \%$ & 0 \\
\hline Non-missing & 159 & $100.0 \%$ & 110 & $100.0 \%$ & \\
\hline \multicolumn{6}{|l|}{ Gender } \\
\hline Missing & 0 & $0.0 \%$ & 0 & $0.0 \%$ & 0 \\
\hline Non-missing & 159 & $100.0 \%$ & 110 & $100.0 \%$ & \\
\hline \multicolumn{6}{|l|}{ Race/Ethnicity } \\
\hline Missing & 5 & $3.1 \%$ & 7 & $6.4 \%$ & 0.24 \\
\hline Non-missing & 154 & $96.3 \%$ & 103 & $93.6 \%$ & \\
\hline \multicolumn{6}{|c|}{ Education level (per NHANES) } \\
\hline Missing & 0 & $0.0 \%$ & 5 & $4.5 \%$ & $0.01^{*}$ \\
\hline Non-missing & 159 & $100.0 \%$ & 105 & $95.5 \%$ & \\
\hline \multicolumn{6}{|l|}{ Health Status } \\
\hline Missing & 0 & $0.0 \%$ & 1 & $0.9 \%$ & 0.41 \\
\hline Non-missing & 159 & $100.0 \%$ & 109 & $99.1 \%$ & \\
\hline \multicolumn{6}{|c|}{ Alcohol Past 6 Months (survey variables) } \\
\hline Missing & 0 & $0.0 \%$ & 2 & $1.8 \%$ & 0.76 \\
\hline Non-missing & 159 & $100.0 \%$ & 108 & $98.2 \%$ & \\
\hline \multicolumn{6}{|c|}{ IDU Past 6 Months (survey variable) } \\
\hline Missing & 1 & $0.6 \%$ & 2 & $1.8 \%$ & 0.57 \\
\hline Non-missing & 158 & $99.4 \%$ & 108 & $98.2 \%$ & \\
\hline \multicolumn{6}{|l|}{ HIV Comorbid } \\
\hline Missing & 0 & $0.0 \%$ & 0 & $0.0 \%$ & 0 \\
\hline
\end{tabular}

Figure 1: Eligibility for Survey Completion and Eligible and Ineligible Surveys Received, Used to Calculate Response Rates*

INSPIRE Participants Eligible for Baseline Survey INSPIRE Participants Eligible for Post-Intervention Survey 


\begin{tabular}{|c|c|c|c|c|c|}
\hline & \multicolumn{2}{|c|}{$\begin{array}{l}\text { Complete Surveys }(\mathrm{N}= \\
159)\end{array}$} & \multicolumn{3}{|c|}{$\begin{array}{l}\text { Partial Surveys ( } N= \\
110)\end{array}$} \\
\hline Non-missing & 159 & $100.0 \%$ & 110 & $100.0 \%$ & \\
\hline \multicolumn{6}{|c|}{ Mental Health Comorbidities } \\
\hline Missing & 3 & $1.9 \%$ & 4 & $3.6 \%$ & 0.45 \\
\hline Non-missing & 156 & $98.1 \%$ & 106 & $96.4 \%$ & \\
\hline \multicolumn{6}{|c|}{ Social Support (Family and/or Friends) } \\
\hline Missing & 0 & $0.0 \%$ & 0 & $0.0 \%$ & 0 \\
\hline Non-missing & 159 & $100.0 \%$ & 110 & $100.0 \%$ & \\
\hline \multicolumn{6}{|c|}{ ER Visits Past 6 Months } \\
\hline Missing & 1 & $0.6 \%$ & 3 & $2.7 \%$ & 0.31 \\
\hline Non-missing & 158 & $99.4 \%$ & 107 & $97.3 \%$ & \\
\hline \multicolumn{6}{|c|}{ Hospital Nights Past 6 Months } \\
\hline Missing & 3 & $1.9 \%$ & 3 & $2.7 \%$ & 0.69 \\
\hline Non-missing & 156 & $98.1 \%$ & 107 & $97.3 \%$ & \\
\hline \multicolumn{6}{|c|}{ Auxiliary Variables } \\
\hline \multicolumn{6}{|l|}{ Insurance Type } \\
\hline Missing & 0 & $0.0 \%$ & 1 & $0.9 \%$ & 0.41 \\
\hline Non-missing & 159 & $100.0 \%$ & 109 & $99.1 \%$ & \\
\hline \multicolumn{6}{|c|}{ Diabetes Comorbid } \\
\hline Missing & 0 & $0.0 \%$ & 0 & $0.0 \%$ & 0 \\
\hline Non-missing & 159 & $100.0 \%$ & 110 & $100.0 \%$ & \\
\hline \multicolumn{6}{|c|}{ History of Incarceration } \\
\hline \multicolumn{6}{|c|}{$\begin{array}{l}\text { Figure 1: Eligibility for Survey Completion and Eligible and Ineligible Surveys Received, Used to Calculate } \\
\text { Response Rates* }\end{array}$} \\
\hline \multicolumn{6}{|c|}{ INSPIRE Participants Eligible for Baseline Survey INSPIRE Participants Eligible for Post-Intervention Survey } \\
\hline
\end{tabular}




\begin{tabular}{|c|c|c|c|c|c|}
\hline \multirow[b]{2}{*}{ Missing } & \multicolumn{2}{|c|}{$\begin{array}{l}\text { Complete Surveys }(\mathrm{N}= \\
159)\end{array}$} & \multicolumn{3}{|c|}{$\begin{array}{l}\text { Partial Surveys }(N= \\
110)\end{array}$} \\
\hline & 53 & $33.1 \%$ & 31 & $28.2 \%$ & 0.37 \\
\hline Non-missing & 106 & $66.7 \%$ & 79 & $71.8 \%$ & \\
\hline \multicolumn{6}{|c|}{$\begin{array}{l}\text { Number of Doctor Appointments in } 6 \\
\text { Months }\end{array}$} \\
\hline Missing & 6 & $3.8 \%$ & 10 & $9.1 \%$ & 0.07 \\
\hline Non-missing & 153 & $96.2 \%$ & 100 & $90.9 \%$ & \\
\hline \multicolumn{6}{|c|}{ Income - monthly } \\
\hline Missing & 5 & $3.1 \%$ & 5 & $4.5 \%$ & 0.55 \\
\hline Non-missing & 154 & $96.9 \%$ & 105 & $95.5 \%$ & \\
\hline \multicolumn{6}{|l|}{ Marital Status } \\
\hline Missing & 0 & $0.0 \%$ & 6 & $5.5 \%$ & $0.004^{\star}$ \\
\hline Non-missing & 159 & $100.0 \%$ & 104 & $94.5 \%$ & \\
\hline \multicolumn{6}{|c|}{ Alcohol Past 6 Months (Clinical variable) } \\
\hline Missing & 4 & $2.5 \%$ & 4 & $3.6 \%$ & 0.59 \\
\hline Non-missing & 155 & $97.5 \%$ & 102 & $92.7 \%$ & \\
\hline \multicolumn{6}{|c|}{ IDU Past 6 Months (Clinical Variable) } \\
\hline Missing & 7 & $4.4 \%$ & 6 & $5.5 \%$ & 0.69 \\
\hline Non-missing & 152 & $95.6 \%$ & 104 & $94.5 \%$ & \\
\hline \multicolumn{6}{|l|}{ Survey Type } \\
\hline Missing & 0 & $0.0 \%$ & 0 & $0.0 \%$ & 0 \\
\hline Non-missing & 159 & $100.0 \%$ & 110 & $100.0 \%$ & \\
\hline \multicolumn{6}{|c|}{ *Significant at the $a=.05$ level } \\
\hline \multicolumn{6}{|c|}{$\begin{array}{l}\text { Figure 1: Eligibility for Survey Completion and Eligible and Ineligible Surveys Received, Used to Calculate } \\
\text { Response Rates* }\end{array}$} \\
\hline INSPIRE Partic & ey I & articipant & ble $\mathrm{f}$ & nter & urvey \\
\hline
\end{tabular}

Overall, respondent satisfaction with their INSPIRE care coordinators, clinicians, and the health promotion sessions was very high (Fig. 2)-more than $80 \%$ of the subset of participants responding to the post-intervention survey selected "Agree" or "Strongly Agree" with positive statements regarding these aspects of the INSPIRE intervention.

Respondents tended to report very high medication adherence-more than $80 \%$ of respondents reported missing one dose of HCV medication or fewer in the preceding four weeks of treatment, and more than $80 \%$ reported 
following their treatment time schedule every day.

Changes in Health Behaviors and Self-Efficacy, Baseline to Post-Intervention

Completion of INSPIRE was not associated with a change in HCV knowledge. Compared with an average baseline score of $82.4 \%$, the average post-intervention score was $75.3 \%$; however, after adjustment in the GEE model, the decrease was non-significant (adjusted average decrease: $-4.01 \%$; $\mathrm{Cl}-9.10-1.08 \% ; \mathrm{p}=0.12$ ). Examined individually, two knowledge questions showed significant response changes, including if coughing and sneezing can spread HCV, and if a person can be re-infected with HCV after being cured. Although both questions showed, against expectation, statistically significant decreases in HCV knowledge, these results are not surprising given the high level of HCV knowledge at baseline (Table 3). 
Table 3

Project INSPIRE Survey Respondent Performance on HCV Knowledge Scale, Baseline and Post-Intervention Surveys

\begin{tabular}{|c|c|c|c|c|c|}
\hline & \multicolumn{2}{|c|}{ Baseline } & \multicolumn{3}{|c|}{$\begin{array}{l}\text { Post- } \\
\text { Intervention }\end{array}$} \\
\hline & $\mathrm{n}$ & $\begin{array}{l}\% \\
\text { Correct }\end{array}$ & $n$ & Correct & $\begin{array}{l}\mathrm{p}- \\
\text { value }\end{array}$ \\
\hline $\begin{array}{l}\text { 1. Can people who are living with hepatitis } \mathrm{C} \text { damage their liver } \\
\text { when they drink alcohol? }\end{array}$ & 116 & 95.6 & 148 & 94.6 & 0.84 \\
\hline $\begin{array}{l}\text { 2. Is there a hepatitis } C \text { vaccine that can be used to prevent } \\
\text { people from getting infected with the hepatitis } C \text { virus? }\end{array}$ & 110 & 57.3 & 147 & 50.3 & 0.26 \\
\hline $\begin{array}{l}\text { 3. Is it a good idea for people living with hepatitis } C \text { to be } \\
\text { vaccinated against hepatitis } A \text { and } B \text { ? }\end{array}$ & 113 & 85.0 & 149 & 77.2 & 0.10 \\
\hline $\begin{array}{l}\text { 4. Is it true that most people who inject street drugs with used } \\
\text { needles are infected with hepatitis C? }\end{array}$ & 113 & 85.0 & 146 & 78.8 & 0.19 \\
\hline $\begin{array}{l}\text { 5. Can people live with hepatitis } C \text { for many years without } \\
\text { knowing that they are infected with the virus? }\end{array}$ & 115 & 87.8 & 146 & 91.8 & 0.29 \\
\hline $\begin{array}{l}\text { 6. Can someone get infected with hepatitis } \mathrm{C} \text { by snorting } \\
\text { cocaine with shared straws, rolled money, etc.? }\end{array}$ & 112 & 57.1 & 146 & 50.0 & 0.24 \\
\hline $\begin{array}{l}\text { 7. Does using new (i.e., never used before) needles, syringes, and } \\
\text { equipment reduce the risk of being infected with hepatitis C? }\end{array}$ & 113 & 81.4 & 149 & 91.9 & 0.19 \\
\hline $\begin{array}{l}\text { 8. Could babies born to mothers who are living with hepatitis } C \\
\text { also become infected with hepatitis } C \text { ? }\end{array}$ & 110 & 83.6 & 147 & 74.8 & 0.19 \\
\hline $\begin{array}{l}\text { 9. Can HIV + men who have sex with men get infected with } \\
\text { hepatitis C through sex? }\end{array}$ & 111 & 85.6 & 148 & 79.1 & 0.17 \\
\hline 10. Can coughing and sneezing spread hepatitis $C$ ? & 112 & 83.0 & 147 & 70.7 & $0.02 *$ \\
\hline 11. Can someone infected with the hepatitis $\mathrm{C}$ virus be cured? & 113 & 97.3 & 149 & 98.0 & $\mathrm{~N} / \mathrm{A}^{\star *}$ \\
\hline $\begin{array}{l}\text { 12. Can someone who has been cured of hepatitis } \mathrm{C} \text { become re- } \\
\text { infected with hepatitis } \mathrm{C} \text { ? }\end{array}$ & 111 & 82.9 & 148 & 723 & $0.04 *$ \\
\hline $\begin{array}{l}\text { 13. Can people get infected with hepatitis } \mathrm{C} \text { from tattoos and } \\
\text { body piercing? }\end{array}$ & 113 & 90.3 & 146 & 82.2 & 0.06 \\
\hline 14. Can hepatitis $\mathrm{C}$ be spread through hugs or handshakes? & 114 & 94.7 & 149 & 91.9 & 0.35 \\
\hline$*$ Significant at the $a=.05$ level & & & & & \\
\hline
\end{tabular}

The adjusted GEE models showed that having completed INSPIRE was not significantly associated with changes in respondent overall health (adjusted OR $=0.88,95 \% \mathrm{Cl}: 0.56-1.36$ ). However, discharged INSPIRE participants showed a decrease in the odds of (across categories) ER visits (aOR $=0.34,95 \% \mathrm{Cl}: 0.20-0.57$ ) and a decrease in the odds of (across categories) hospital visits (aOR $=0.30,95 \% \mathrm{Cl}: 0.16-0.57)$ compared with when participants 
were first enrolled in INSPIRE. A decrease in alcohol and drug use (over the past 6 months) was associated with having received the INSPIRE intervention $(\mathrm{aOR}=0.35,95 \% \mathrm{Cl}: 0.18-0.6$ 9and $\mathrm{aOR}=0.03,95 \% \mathrm{Cl}: 0.03-0.34)$.

Completion of INSPIRE was associated with a 0.34 -point (Cl: $0.08-0.61)$ increase in self-efficacy score $(p=0.01)$. Given a maximum measure score of 5 , this change represents a $6.8 \%$ increase $(\mathrm{Cl} 1.6-12.2 \%)$ in the average score. Results from the sensitivity analysis using respondents' mean self-efficacy score instead of the factor score also showed a positive association between INSPIRE and reported self-efficacy with a 0.23-point $(\mathrm{Cl} 0.05-$ $0.41)$ increase $(4.6 \%$; $\mathrm{Cl} 1.0-8.2 \%)(p=0.01)$.

\section{Discussion}

This analysis indicates a positive association between participation in Project INSPIRE and improvement in selfreported health outcomes. Survey respondents, as with INSPIRE participants generally, were high-need-the majority were low-income, had less than a high-school education, experienced numerous comorbidities, and grappled with both substance use and mental health issues (unpublished data, NYC DOHMH). INSPIRE was wellliked and well-received by respondents and successful in improving HCV-related health behavior including reducing ED visits, hospitalizations, alcohol use, and drug use. Post-intervention survey respondents showed high satisfaction with INSPIRE, consistently agreeing with positive statements and disagreeing with negative statements about their care coordinator, clinician, and health promotion sessions. However, social desirability bias might have influenced some participants to answer more favorably-although it was explained to participants that their responses would not be viewed by their care team, they may not have fully realized this, especially given that their care coordinator distributed the survey. However, the overall high level of satisfaction does suggest that the INSPIRE intervention was well-received by the participants who completed the survey. This also suggests that intervention recruitment might have benefited from referrals from satisfied patients to their HCV-positive peers.

The health promotion sessions generated more mixed satisfaction responses than other project aspectsapproximately $70 \%$ of respondents "disagreed" or "strongly disagreed" with negative statements compared with approximately $80 \%$ of respondents when evaluating their care coordinators and HCV medical providers. These findings were consistent with results from qualitative focus groups conducted to evaluate the INSPIRE model (unpublished data, NYC DOHMH). Participants from the focus groups indicated that they were sometimes dissatisfied with the quantity and length of sessions. The INSPIRE protocol was written to deliver 7 health promotion sessions, each scheduled to last 30 minutes, using content not necessarily tailored to each participant's knowledge or health literacy level. Future iterations of the program might require changes to the health promotion sessions to improve satisfaction.

Although INSPIRE aimed to improve participant HCV knowledge, the current analysis suggests this was not achieved. The lack of positive change might be because of a high average level of knowledge among the baseline group (83.3\% on the HCV Knowledge Scale). With regression toward the mean, statistically significant increases in knowledge would be difficult to observe when the baseline score is already quite high (16). Regardless of initial knowledge level, lack of significant improvement suggests a need for improved HCV messaging in the program. In addition, previous research has described that HCV infected individuals can develop cognitive impairment, directly due to the virus (37) and/or their potentially past use of alcohol and drugs. It may thus be important to account for this in the design of health promotion modules so that content is

Page $17 / 24$ 
delivered at an appropriate level and at multiple time points to maximize participant comprehension and retention.

Results from the multivariable models assessing various self-reported health behaviors point toward INSPIRE's effectiveness in achieving other program goals. Completion of INSPIRE was associated with significant reductions in self-reported ED visits, hospitalizations, alcohol use, and injection drug use. Increased self-efficacy between enrollment and completion of INSPIRE suggests achievement of one of INSPIRE's main program goals: improving participants' ability to manage their own health and navigate the healthcare system.

As a demonstration project, INSPIRE was intended to evaluate the effect of providing tailored care coordination on treatment outcomes for HCV patients. This study shows that the advantages of INSPIRE might go beyond just clinical outcomes such as treatment initiation and SVR. These findings suggest that improvements in specific health behaviors and perceived self-efficacy could be expected after the participation in and completion of Project INSPIRE. These improved longer-term outcomes could be of interest to groups such as insurance companies and managed care organizations that might be concerned about the upfront added costs of care coordination but are interested in the possible savings from decreased ED visits, inpatient hospitalizations, and improved self-efficacy, which has been linked to better primary care outcomes and reduced costs (38).

There are some limitations associated with this study. Non-response and selection bias likely played a large role in these results. The response rates for the baseline and post-intervention survey were very low $-14.0 \%$ and $9.9 \%$, respectively, for all returned surveys-particularly compared with the $>40 \%$ response rate for mailed surveys reported in other studies (39). The low response rates limit our ability to generalize the results of this study to the entire INSPIRE cohort. Also, the majority of returned surveys were unpaired, limiting our ability to draw conclusions about changes in individuals.

Although edits to the survey were minimal, initial iterations might have been less appealing to complete, thus influencing who responded and how they answered the survey questions. Survey distribution was not uniform across care coordinators-although the survey protocol stated all eligible participants should receive the survey, no formal process ensured care coordinators distributed the survey as instructed with the same level of information, such as whom to contact for questions, purpose of the survey or possibly providing assistance completing the survey. Furthermore, we were not able to perform an assessment of response bias comparing survey respondents with the entire INSPIRE cohort because of IRB restrictions.

Care coordinators and respondents highlighted further limitations of the survey. These issues included a survey literacy level higher than that of some of the respondents, the length of the survey, and confusion around the wording of some questions. While the research team sought to answer and follow up on any respondent questions, we were not able to contact all respondents who potentially had misunderstandings. This might have created variability in response, biasing results. Confusion might also have been caused by a simultaneous ongoing survey distributed by outside INSPIRE evaluators hired by the funder, possibly causing participants to believe this survey was a duplicate of a previously completed survey and contributing to a lower response rate.

Despite these limitations, the findings from this study provide insights into INSPIRE participants' perspectives on HCV-related care coordination services. Based on the analyses presented here, the program successfully improved respondent health-related behaviors, including self-perceived ability to manage their own health, and these results complement past findings that suggest the intervention is worth replicating in the future, including 
with other chronic medical conditions. Noted improvements in this complex population also highlight the positive impact this model may have in populations facing similar barriers to care and should be considered in future public health intervention planning for persons with chronic illness. Further research will be key to understanding which components of INSPIRE are the most effective at improving clinical, behavioral, and overall health outcomes and how to address possible areas for program improvement.

\section{Abbreviations}

$\mathrm{HCV}$

hepatitis C

NYC

New York City

NYC DOHMH

New York City Department of Health and Mental Hygiene

ED

emergency department

SVR

sustained virologic response

GSRH

general self-rated health question

EFA

Exploratory factor analysis

AAPOR

American Association for Public Opinion Research

MI

multiple imputation

MNAR

missing not at random

GEE

generalized estimating equation

ALR

alternating logistic regression

\section{Declarations}

\section{Ethics approval and consent to participate}

The survey and methods described above were reviewed by the two clinical partners, Mount Sinai Hospital and Montefiore Medical Center, and approved by the Institutional Review Boards at each respective clinical site and at the NYC DOHMH (IRB Protocol 16-015). Study participants were required to complete and sign a written informed consent form. When written consent was not gained from a participant the survey was excluded from the research.

Consent for publication 
Not applicable

Availability of data and materials

The datasets generated and/or analyzed during the current study are not publicly available due to patient confidentiality but are available from the corresponding author on reasonable request and upon obtaining institutional review board approval and executing a data use agreement approved by the legal departments of participating institutions.

Competing interests

The authors have no competing interests to report

Funding

The project described was supported by Grant Number 1C1CMS331330-01-00 from the Department of Health and Human Services, Centers for Medicare \& Medicaid Services.

\section{Authors' contribution}

RD contributed to the design, data acquisition, analysis and interpretation, drafting, editing and approval of the final manuscript. AM contributed to the data acquisition, analysis and interpretation, drafting and editing of the final manuscript. CD contributed to the data acquisition, analysis and interpretation, drafting and editing of the final manuscript. MB contributed to the overall study supervision, conception, design, data interpretation, editing the manuscript and final approval of the manuscript. SR contributed to the design, acquisition of data, editing the manuscript and approving the final version. BW contributed to the design, acquisition of data, editing the manuscript and approving the final version. FL, contributed to the overall study supervision, conception, design, data interpretation, editing the manuscript and final approval of the manuscript.

\section{Acknowledgements}

Icahn School of Medicine at Mount Sinai: Ponni Perumalswami, Jeff Weiss, Douglas Dieterich, Ashley Pichardo, Anastasia Teper, Samara Washington, Celia Grace Murnock, Joy Cambe, Rachel Potter, Natasha Toussaint, Brigitte Buquez, De Shaunda Page, and Glyn Singleton

Montifiore Medical Center: Alain Litwin, Shuchin Shukla, Paul Meissner, Frances Rodriquez, Tanesha Pommells, Rose Chang, Beatriz Casiano, Stephanie Ventura, and Christine Corsino and the Care Coordination and Peer Navigation teams.

NYC DOHMH: Mary Ford, Miranda Moore, Sharon Greene, and Ann Winters

\section{References}

1. Armstrong GL, Wasley A, Simard EP, McQuillan GM, Kuhnert WL, Alter MJ. The prevalence of hepatitis C virus infection in the United States, 1999 through 2002. Ann Intern Med. 2006;144(10):705-14.

2. Hofmeister MG, Rosenthal EM, Barker LK, Rosenberg ES, Barranco MA, Hall EW, et al. Estimating Prevalence of Hepatitis C Virus Infection in the United States, 2013-2016. Hepatology. 2018. 
3. Bocour A, Greene SK, Laraque F, Winters A. Estimating the prevalence of chronic hepatitis $\mathrm{C}$ virus infection in New York City, 2015. Epidemiology and infection. 2018:1-6.

4. Denniston MM, Jiles RB, Drobeniuc J, Klevens RM, Ward JW, McQuillan GM, et al. Chronic hepatitis C virus infection in the United States, National Health and Nutrition Examination Survey 2003 to 2010. Ann Intern Med. 2014;160(5):293-300.

5. Do A, Mittal Y, Liapakis A, Cohen E, Chau H, Bertuccio C, et al. Drug authorization for Sofosbuvir/Ledipasvir (Harvoni) for chronic HCV infection in a real-world cohort: A new barrier in the HCV care cascade. PloS one. 2015;10(8):e0135645.

6. McGowan CE, Fried MW. Barriers to Hepatitis C Treatment. Liver International. 2012;32(0 1):151-6.

7. Ford MM, Johnson N, Desai P, Rude E, Laraque F. From Care to Cure: Demonstrating a Model of Clinical Patient Navigation for Hepatitis C Care and Treatment in High-Need Patients. Clin Infect Dis. 2017;64(5):68591.

8. Irvine MK, Chamberlin SA, Robbins RS, Myers JE, Braunstein SL, Mitts BJ, et al. Improvements in HIV care engagement and viral load suppression following enrollment in a comprehensive HIV care coordination program. Clin Infect Dis. 2015;60(2):298-310.

9. Gilman B, Anglin G, Bogen K, Chen A, Conwell L, Dale S, et al. Evaluation of the Round Two Health Care Innovation Awards (HCIA R2): Second annual report Mathematica Policy Research; 2017 August.

10. Deming R, Ford MM, Moore MS, Lim S, Perumalswami P, Weiss J, et al. Evaluation of a hepatitis C clinical care coordination programme's effect on treatment initiation and cure: A surveillance-based propensity score matching approach. J Viral Hepat. 2018.

11. Mason K, Dodd Z, Sockalingam S, Altenberg J, Meaney C, Millson P, et al. Beyond viral response: A prospective evaluation of a community-based, multi-disciplinary, peer-driven model of HCV treatment and support. International Journal of Drug Policy. 2015;26(10):1007-13.

12. Guadagnolo BA, Cina K, Koop D, Brunette D, Petereit DG. A pre-post survey analysis of satisfaction with health care and medical mistrust after patient navigation for American Indian cancer patients. Journal of health care for the poor and underserved. 2011;22(4):1331-43.

13. Proeschold-Bell RJ, Yao J, Gorthala S, Muir A. Development of a measure of hepatitis C-alcohol knowledge. Journal of Alcohol and Drug Education. 2014;58(3):7-18.

14. Balfour L, Cooper C, Tasca GA, Kane M, Kowal J, Garber G. Evaluation of health care needs and patient satisfaction among hepatitis $\mathrm{C}$ patients treated at a hospital-based, viral hepatitis clinic. Canadian Journal of Public Health. 2004;95(4):272-7.

15. DeSalvo KB, Fan VS, McDonell MB, Finn SD. Predicting mortality and healthcare utilization with a single question. Health services research. 2005;40(4):1234-46.

16. Balfour L, Kowal J, Corace KM, Tasca GA, Krysanski V, Cooper CL, et al. Increasing public awareness about hepatitis C: development and validation of the brief hepatitis $\mathrm{C}$ knowledge scale. Scandinavian Journal of Caring Sciences. 2009;23(4):801-8.

17. Hibbard JH, Mahoney ER, Stockard J, Tusler M. Development and testing of a short form of the Patient Activation Measure. Health services research. 2005;40(6 Pt 1):1918-30.

18. Oetzel J, Wilcox B, Avila M, Hill R, Archiopoli A, Ginossar T. Patient-provider interaction, patient satisfaction, and health outcomes: testing explanatory models for people living with HIV/AIDS. AIDS Care. 
2015;27(8):972-8.

19. Galassi JP, Schanberg R, Ware WB. The Patient Reactions Assessment: A brief measure of the quality of the patient-provider medical relationship. Psychological Assessment. 1992;4(3):346.

20. DiStefano C, Zhu M, Mindrila D. Understanding and using factor scores: Considerations for the applied researcher Practical Assessment, Research \& Evaluation. 2009;14(20).

21. Holgado-Tello FP, Chacón-Moscoso S, Barbero-García I, Vila-Abad E. Polychoric versus Pearson correlations in exploratory and confirmatory factor analysis of ordinal variables. Quality \& Quantity. 2010;44:153-66.

22. Roberts NJ, Kidd L, Dougall N, Patel IS, McNarry S, Nixon C. Measuring patient activation: The utility of the Patient Activation Measure within a UK context-Results from four exemplar studies and potential future applications. Patient Education and Counseling. 2016;99(10):1739-46.

23. Skolasky RL, Mackenzie EJ, Riley LH, Wegener ST. Psychometric properties of the Patient Activation Measure among individuals presenting for elective lumbar spine surgery. Quality of Life Research. 2009;18(10):135766.

24. Williams B, Onsman A, Brown T. Exploratory factor analysis: A five-step guide for novices. Australasian Journal of Paramedicine. 2014;8(3).

25. Henson RK, Roberts JK. Use of exploratory factor analysis in published research. Educational and Psychological Measurement. 2006;66(3):393-416.

26. Costello AB, Osborne JW. Best practices in exploratory factor analysis: four recommendations for getting the most from your analysis. Practical Assessment, Research \& Evaluation. 2005;10(7).

27. Yong AG, Pearce S. A beginner's guide to factor analysis: Focusing on exploratory factor analysis. Quantitative Methods for Psychology. 2013;9(2):79-94.

28. The American Association for Public Opinion Research. Standard Definitions: Final Dispositions of Case Codes and Outcome Rates for Surveys. 2016.

29. Research TAAfPO. Survey Outcome Rate Calculator 4.0. http://www.aapor.org/aapor_main/media/mainsitefiles/response-rate-calculator-4-0-clean-18-may2016.xIsx2016.

30. Chumbler NR, Neugaard B, Kobb R, Ryan P, Qin H, Joo Y. Evaluation of a care coordination/home-telehealth program for veterans with diabetes. Evaluation \& the Health Professions. 2005;28(4):464-78.

31. Derrick B, Dobson-Mckittrick A, Toher D, White P. Test statistics for comparing two proportions with partially overlapping samples. Journal of Applied Quantitative Methods. 2015;10(3).

32. Schafer JL, Graham JW. Missing data: our view of the state of the art. Psychol Methods. 2002;7(2):147-77.

33. Buuren Sv. Multiple imputation of discrete and continuous data by fully conditional specification. Statistical Methods in Medical Research. 2007;16(3):219-42.

34. Raghunathan T, Solenberger P, Berglund P, van Hoewyk J. IVEware: Imputation and Variance Estimation Software. 0.3 ed2016.

35. Preisser JS, Arcury TA, Quandt SA. Detecting patterns of occupational illness clustering with alternating logistic regressions applied to longitudinal data. American journal of epidemiology. 2003;158(5):495-501.

36. Gill J, King G. What to do when your Hessian is not invertible: Alternatives to model respecification in nonlinear estimation. Sociological Methods \& Research. 2004;33(1):54-87. 
37. Mathew S, Faheem M, Ibrahim SM, Iqbal W, Rauff B, Fatima K, et al. Hepatitis C virus and neurological damage. World Journal of Hepatology. 2016;8(12):545-56.

38. Bodenheimer T, Lorig K, Holman H, Grumbach K. Patient self-management of chronic disease in primary care. Journal of the American Medical Association. 2002;288(19):2469-75.

39. Yehuda $\mathrm{B}$, Brooks $\mathrm{CH}$. Survey response rate levels and trends in organizational research. Human Relations. 2008;61(8):1139-60.

The data analysis for this paper was generated using SAS/STAT software, Version 9.4 of the SAS System for Windows. Copyright (c) 2013 SAS Institute Inc. SAS and all other SAS Institute Inc. product or service names are registered trademarks or trademarks of SAS Institute Inc., Cary, NC, USA.

\section{Figures}

INSPIRE Participants Eligible for Baseline Survey

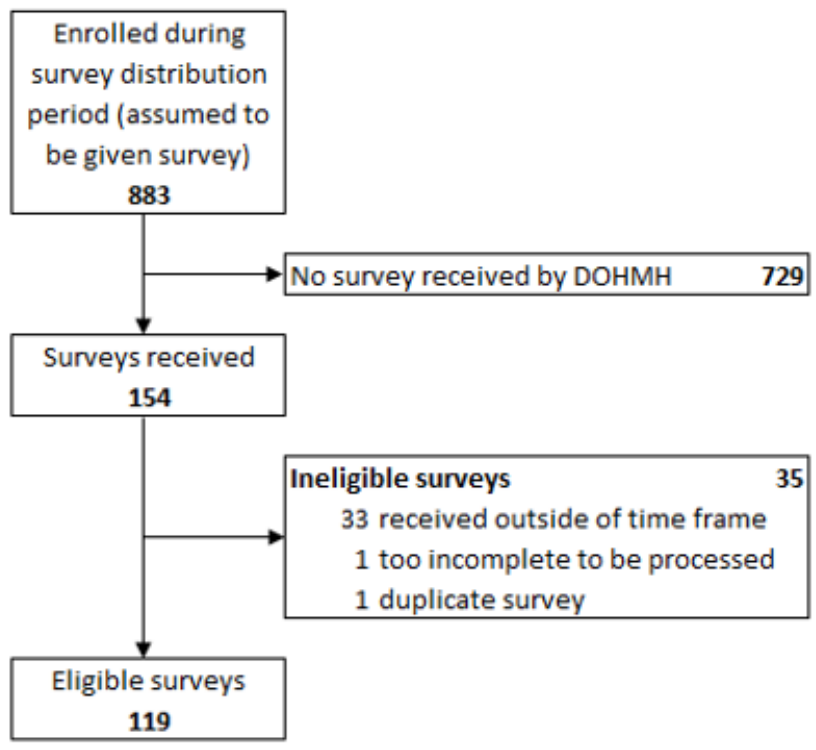

INSPIRE Participants Eligible for Post-Intervention Survey

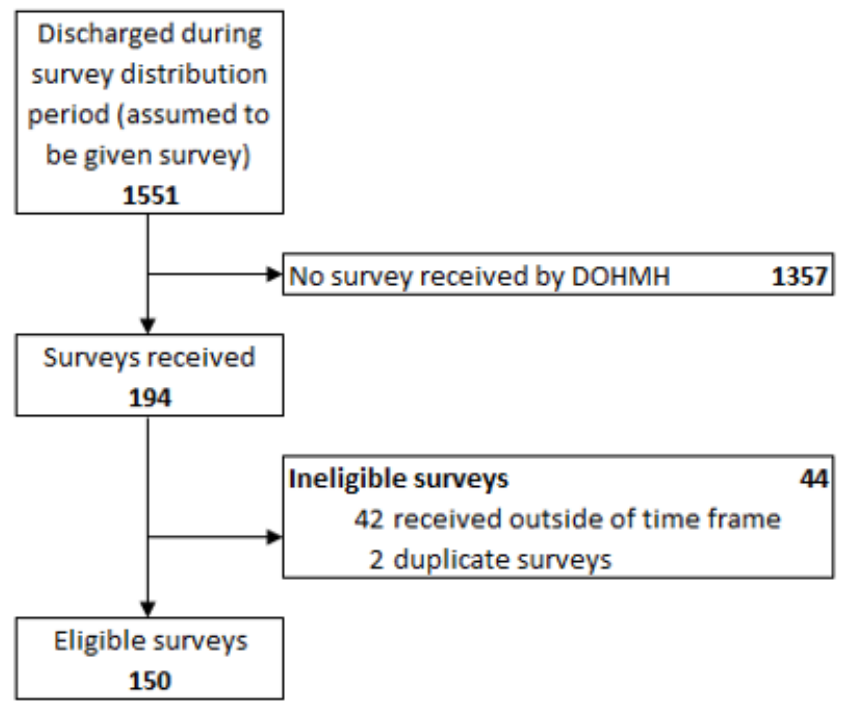

*Baseline surveys were distributed between August 2016 and March 2017 and post-intervention surveys were distributed between November 2016 and September 2017. Surveys considered to be received outside of time frame include patients who received and completed a survey but upon review of enrollment dates were not eligible for survey distribution

\section{Figure 1}

Eligibility for Survey Completion and Eligible and Ineligible Surveys Received, Used to Calculate Response Rates* 


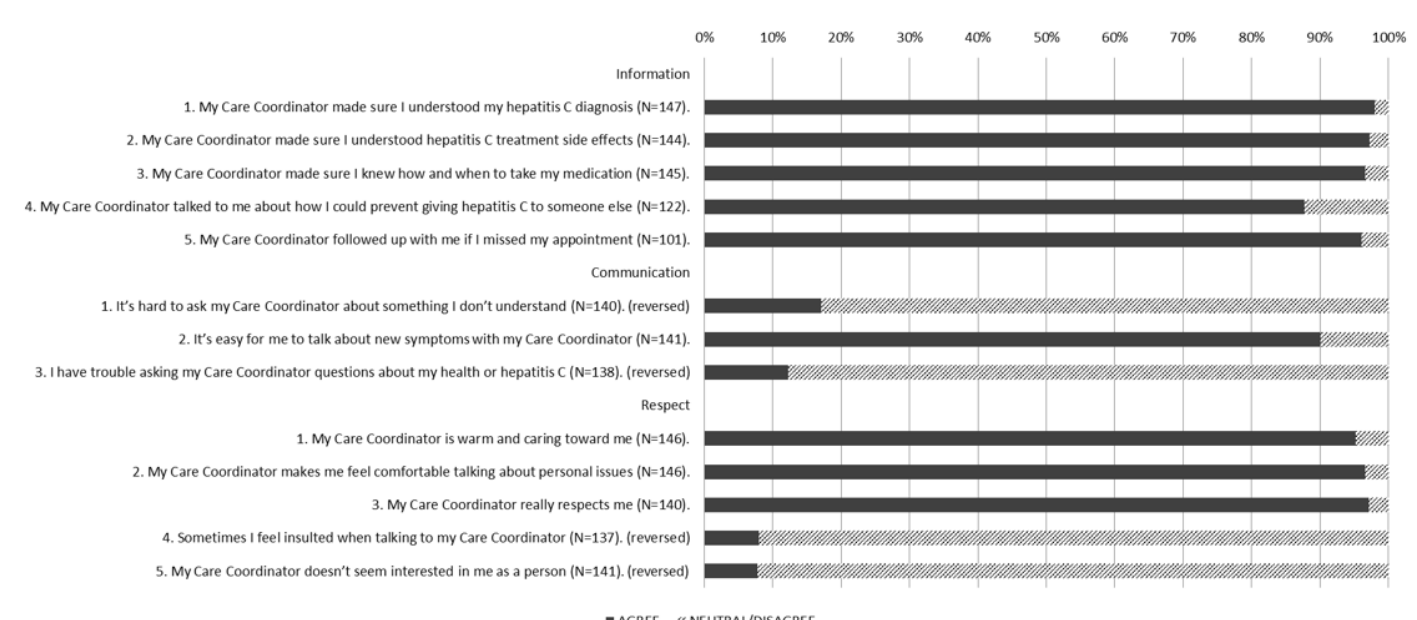

- AGREE \% NEUTRAL/DISAGREE

"Reversed" questions indicate that the desired response is "Neutral/Disagree" while the desired response to all other questions are "Agree"

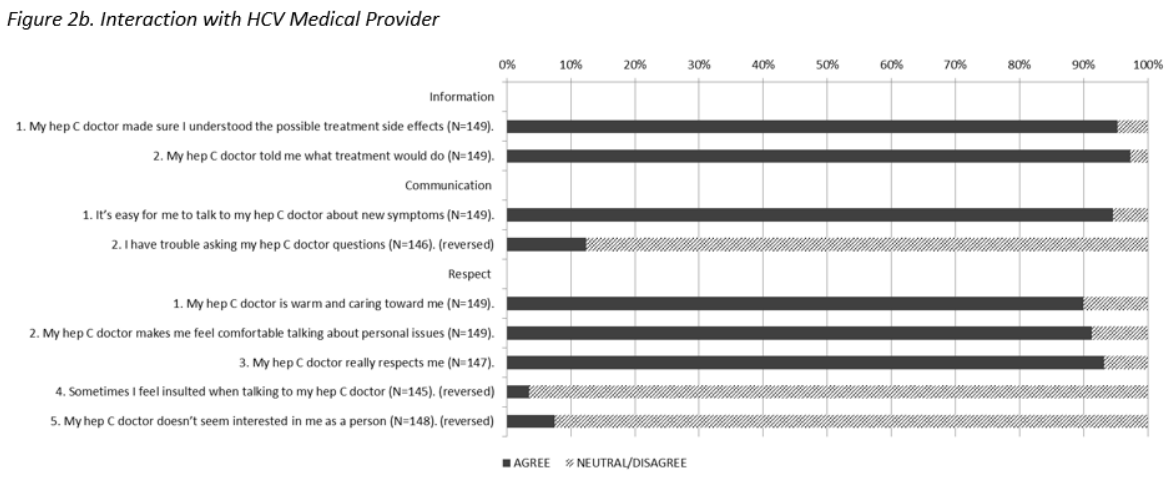

Figure 2c. Satisfaction with health promotion sessions

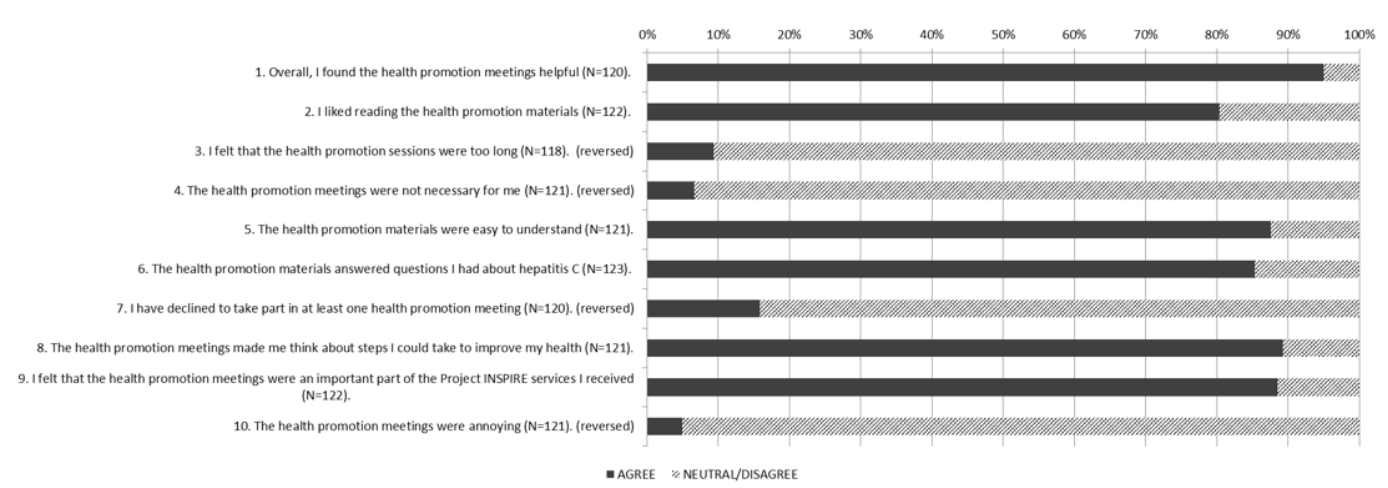

Figure 2

Post-Intervention Respondent Satisfaction (a) Interaction with Care Coordinator, (b) Interaction with HCV Medical Provider, and (c) Health Promotions 